\title{
Elecciones a Cortes en el distrito de Montilla Años 1903-1905-1907
}

\author{
JOSEFA POLONIO ARMADA
}

\section{INTRODUCCION}

El distrito electoral de Montilla, integrádo por los pueblos de Montilla, Aguilar de la Frontera, Montemayor, Castro del Río y Espejo ha sido -y aún continúa siéndolo- uno de los enclaves cordobeses donde las contradicciones políticas e ideológicas son más fuertes.

Junto al caciquismo más descarado y humillante de Aguilar o Montemayor encontramos al más solapado pero no por ello menos real de Montilla; tan bien escondido que ha pasado por ser un pueblo sin caciques, donde la mayor parte de los votantes son republicanos. Cabe preguntarse quiénes son esos republicanos, y dejar bien claro que republicano no es igual a izquierdista.

En un intento de clarificar las prácticas caciquiles en este distrito, nada mejor que acogerse a las actas más conflictivas de la primera década del siglo.

1903 supone el triunfo de los conservadores. Durante la campaña se recurre a todo tipo de subterfugios y las votaciones se ven alteradas por compra de votos y amenazas en varios lugares.

1905 es el año de la revancha de los liberales. Sorprende ver cómo toda la aldea de Zapateros se pone de acuerdo para votar, como un solo hombre, al mismo candidato oficialista. El escándalo que se organiza es mayúsculo.

1907 tiene otro interés: marca la retirada del candidato tradicional del partido Liberal Demócrata, la división de este partido y el clamor por la alianza monárquica frente al monstruo republicano que trata de ganarse a los sectores anarquistas de Espejo y Castro del Río. La votación no recoge incidentes, pero la campaña es de lo más interesante.

\section{FUENTES}

Para la realización del presente trabajo se han manejado las siguientes fuentes: 


\section{Para las elecciones y actos electorales:}

a.-Las actas del Escrutinio General, que se encuentran en el Archivo Municipal de Montilla, cabeza del Distrito. En ellas se especifican los nombres de los candidatos y los votos obtenidos en cada pueblo. Además, queda constancia de los incidentes más graves producidos durante la votación y el escrutinio.

b.- La prensa local montillana, que da cuentas del estado de la opinión en los círculos más politizados y reseña los actos electorales que se llevan a cabo en Montilla y en todo el Distrito. En estos años se publican -El Aviso* y .Vida Nueva*, que se define como semanario liberal.

c.- La prensa conservadora cordobesa, que da una información

bastante detallada de la campaña y sus resultados, siempre desde su particular sesgo político, contrapunto de la prensa local liberal. El diario consultado es «El Defensor de Córdoban.

\section{Para los acontecimientos colaterales:}

a.- Actas Capitulares: En ellas quedan reflejados todos los actos administrativos del Ayuntamiento, y, por tanto, permiten conocer las cacicadas que se comenten, siempre leyendo entre líneas. Se han utilizado sólo las de Montilla, por ser el lugar donde el mito dice que no hay caciques.

b.- Correspondencia oficial: Para conocer aspectos concretos del desarrollo de la campaña y actos electorales.

\section{LA SITUACION POLITICA EN LA PRIMERA DECADA DEL SIGLO}

El marco político en el que se desarrolla la etapa estudiada es el de la Constitución de 1876, nacida de un consenso de fuerzas monárquicas bajo los auspicios de Cánovas del Castillo, y tomando como base la Constitución moderada de 1845 y algunos principios de la revolución de 1868 . Se trata por tanto de un producto híbrido que intenta la política de «lo hacedero*.

La forma de gobierno es la alternancia de partidos monárquicos que, una vez en el poder por designio real, se fabrican unas Cortes a medida. Los partidos están creados de forma artificial, pero aún más artificiales son las crisis de gobierno y la estridencia de la manipulación de las elecciones.

El Pacto de El Pardo dotaría a España de un sistema político estable, duradero, pero falso y alejado de la realidad social. Un sistema que llegaría a integrar en él incluso a los líderes republicanos y al naciente socialismo,que aceptaron un juego pseudodemocrático y se presentaban a unas elecciones amañadas que quedaban legitimadas con su presencia en las Cortes.

Los dos partidos del turno son un conglomerado de grupos que obedecen más a su jefe inmediato que al jefe del partido. Hasta 1885 , Cánovas fue el jefe indiscutible del partido Liberal Conservador. A partir 
de este momento, la entrega del poder a los liberales hace que salga Romero Robledo, y quede como segundo Francisco Silvela, en desacuerdo con la pólítica de repartos electorales. Piensa que el partido debe corresponder a una iopinión organizada como cosa opuesta a las influencias organizadas. ${ }^{1}$ y todo ello en el marco de una reforma del gobierno municipal. El enfrentamiento con Cánovas llegó a ser abierto, y la oposición a Romero Robledo era frontal.

A la muerte de Silvela, en 1905, el jefe del conservadurismo es Maura. Este político, regeneracionista, es el apóstol de la revolución desde arriba. Intentó dignificar la política acabando con las prácticas caciquiles, pero lo único que consiguió fue terminar con sla ficción de los partidos turnantes, sin sustituirla por un método de gobierno que se dirigiera sinceramente al cuerpo electoral ${ }^{2}$. No reconoció a los liberales como turnantes, pero tampoco se planteó qué sucedería si republicanos y socialistas se volvían contra él.

Los liberales también tenían problemas, pero eran menos dramáticos por la propia constitución interna del partido. Aquí las diferentes tribus se identificaban más claramente y la jefatura de Sagasta quedaba más diluída. Las dos claves del gobierno de los liberales eran la contradicción por agotamiento de su credo, y la corrupción que acabó por matar el capital moral del liberalismo.

Sagasta muere en 1903. Montero Ríos y Moret se disputan la jefatura del partido. En el distrito de Montilla la facción que tiene más fuerza es la del Marqués de la Vega de Armijo, presidente del Congreso en el gobierno liberal de 1905.

Entre los partidos al margen del turno -republicanos y socialistas-, el de mayor influencia en esta etapa es el republicano, la facción liderada por Salmerón. Estaba muy arraigado en la cabeza del distrito, Montilla, donde obtenía bastantes concejales y; casi siempre, la mayoría de votos en las demás elecciones.

El socialismo, que alcanzaría una gran implantación, todavía está en mantillas.

En el distrito, el fervor regeneracionista que impregna la política nacional se manifiesta en una activa campaña de Basilio Paraíso en apoyo de la Unión Nacional, propiciada por Costa, y que, aunque quedó en una rabieta de pequeños comerciantes, dio esperanzas a los elementos más preocupados por el resurgir económico.

Los republicanos, grandes y pequeños líderes, hacen campaña en diferentes pueblos. ${ }^{3}$

(1) R. Carr, España 1808-1975, pag. 351

(2) R. Carr, pag. 459

(3) Díaz del Moral, Historia de las agitaciones campesinas andaluzas, pag. 184. 
Los viejos luchadores anarquistas de tiempos de La Mano Negra volvían a la carga, acompañados de otros muchos con la ilusión del principiante, en los feudos del anarquismo (Espejo, Castro, Montemayor). Como siempre, los burgueses atribuyeron la nueva vida del movimiento obrero a elementos agitadores profesionales, que reparten dinero para provocar levantamientos. "iDinero ęn los centros libertarios! ¡Qué más quisieran los vividores para dejar el oficio, y los propagandistas sinceros y fervorosos (...) que disponer del dinero (...)! ${ }^{4}$ En los círculos obreros se lee prensa anarquista y libros de los grandes ideólogos. Se forman sociedades cooperativas y de socorros mutuos.

En 1903 estalla una oleada de huelgas y desórdenes que son duramente reprimidos 5 .

1905 es un año desastroso. Las cosechas se perdieron por la más horrible de las sequías y el hambre se adueñó de los obreros. Los medios que pusieron las autoridades no sirvieron. Ni rogativas ni reparto de pucheros. Se inician obras públicas con suscripciones particulares, pero no hay con qué pagarlas. En vez de morir resignadamente, los obreros inician motines. La situación se normaliza paulatinamente porque los obreros emigran. El gobierno central no colaboró. Ni envió dinero ni perdonó las contribuciones a los terratenientes, como aconsejaba el Instituto de Reformas Sociales. ${ }^{6}$

También 1907 es un año difícil, pero no se alcanzan las cotas de los años anteriores.

\section{1903}

-Los pueblos tienen el sistema electoral que se merecen. Acaso la mayor acusación que puede hacerse al caciquismo es que retrasó una organización de partidos moderna, fuera de las grandes ciudades, al negar toda posibilidad a un procesogradual de educación política. ${ }^{7}$

El caciquismo, como sistema de clientelismo político con unas fuertes connotaciones sociales y económicas, se apoya en la falta de conciencia política de la gran masa de electores.

Es cierto que el cacique atenta contra la libertad de los electores, pero no son menos ciertas dos cosas:

a.- Que esa libertad no existe, en la mayoría de los casos, por ignorancia del elector.

(4) Díaz del Moral, pag. 187, nota 8.

(5) El Defensor de Córdoba, 18-1II-1903

(6) Díaz del Moral, pag. 220

(7) R. Carr, pag. 357. 
b.- Que el cacique protege a sus clientes de los impuestos, las leyes y las obligaciones para con el Estado.

Por lo tanto, el sistema caciquil sólo se vuelve intolerable cuando una de esas dos condiciones desaparece, y entonces sólo puede mantenerse por la violencia.

En el año 1903, bajo el gobierno conservador presidido por Silvela y con Maura en el Ministerio de Gobernación, se celebran elecciones a Diputados Provinciales y a Cortes, en marzo y abril respectivamente.

El distrito de Montilla cuenta con la presencia de tres candidatos: D. Jerónimo Palma Reyes, republicano federal, personaje muy popular en Montilla. D. Antonio Aguilar Correa, Marqués de la Vega de Armijo, liberal (como los alcaldes de los diferentes ayuntamientos) y anteriormente diputado por el Distrito. D. Juan Burgos Luque, conservador, joven aguilarense de considerable fortuna personal.

La campaña electoral es un contínuo ir y venir de candidatos por todos los pueblos del distrito. Hay algo diferente a las demás campañas: no se han suspendido ayuntamientos ni alcaldes, según las instrucciones de Maura ${ }^{8}$ lo que motiva las quejas de los caciques, acostumbrados al encasillado. Se refiere, naturalmente, a los liberales, que han cerrado filas en torno al Marqués de la Vega de Armijo. Los alcaldes se ven coaccionados por este personaje en contra de los intereses del otro partido monárquico, que en ocasiones anteriores lo había apoyado ${ }^{9}$, y prometen a las asociaciones obreras mejoras que no piensan cumplir ${ }^{10}$.

Hay una amenaza velada por parte conservadora: la oleada de huelgas que provocarán los ‘misioneros* anarquistas que saldrán en carnaval a hacer propaganda ${ }^{11 .}$ Conviene retener este dato, porque días después aparecerán una serie de artículos contra los republicanos, donde se les acusa poco menos que de coqueteo con los elementos anarquistas.

Los liberales se ven atacados en la prensa conservadora; pero se trata más de un ataque que podemos calificar de metódico, formalista, que de un ataque de fondo. Los enemigos reales son los republicanos.

En los días de inicio de la campaña; febrero de 1903, se celebra el XXX aniversario de la proclamación de la I República. En el distrito se celebra en el Café "Las Flores" de Aguilar, el corazón del conservadurismo y patria chica de los candidatos Burgos y Palma, con un banquete muy concurrido que recibe numerosos telegramas de adhesión ${ }^{12}$. Otro ban-

\footnotetext{
(8) Defensor de Córdoba, 7-II-1903

(9) Defensor...13-1I-1903

(10) Defensor... 10-II-1903

(11) Defensor... 11-II-1903. El entrecomillado, igual que el término, es mio.

(12) Defensor... 13-II-1903
} 
quete, esta vez en Córdoba, será el foro donde Lerroux, candidato por La Rambla y una de las bestias negras de la prensa conservadora hable contra la Iglesia y el trono y a favor de la unión de todos los republicanos. Cualquier acto de este signo, sea cual sea el lugar donde se celebra, lleva su crítica correspondiente. Negativa, por supuesto ${ }^{13}$. Así, la asamblea celebrada para reunificar el republicanismo, se ve tachada de tender hacia el socialismo marxista y el anarquismo y se ve condenada al fracaso. Tenían buena visión de futuro los corresponsales conservadores ${ }^{14}$. Pocos días después, el 6 de marzo, se celebraría un mítin en el Campo de la Verdad que pondría de manifiesto la división interna de los republicanos y el escaso apoyo de los socialistas ${ }^{15}$.

La división interna de los republicanos se resalta casi a diario, como si fuera el único partido dividido, buscando quizá ocultar la propia crisis de liderazgo. El programa republicano se ve criticado y ridiculizado. Se reproducen fragmentos de zarzuela que, a decir de la prensa conservadora, los retratan ${ }^{16}$. O se califica de sidea más que rara, absurdan,la de la Juventud Federal de disolver la Guardia Civil, por más que se reconozcan que hay "excesos de celo y abuso de poder" que deben ser corregidos ${ }^{17}$. $\mathrm{O}$, incluso, se pide la detención por blasfemia de uno de los oradores del mítin del sábado de gloria de 1903 en Aguilar, el llamado Miguel Baena (a) El Reptil, montillano deportado por los sucesos de 1873, que llamó sinvergüenzas y canallas a clérigos y conservadores ${ }^{18}$.

También los liberales atacan a los republicanos, aunque reseñan abusos conservadores ${ }^{19}$. En cambio, ven retratados todos los suyos en la prensa conservadora. Abusos que, en el caso de Montilla, se pueden seguir por las Actas capitulares.

Las alcaldadas se suceden tan rápidamente que los conservadores añoran el despotismo de los señores feudales. Citando textualmente, ‘El alcalde de Aguilar ha hecho que los empleados del Municipio abandonen sus cargos y se dediquen a la busca y captura de votos. ${ }^{20}$. Si hacemos caso de esta prensa, se presiona a los dueños de fincas, jornaleros y pobres negando la vigilancia de las fincas de los conservadores ${ }^{21}$ impo-

(13) Defensor... 26-II-1903

(14) .Los republicanos. 20-II-1903 Defensor...

(15) Defensor, 7-III-1903

(16) Defensor, 15-IV-1903

(17) Defensor, 13-IV-1903

(18) .Mitin republicano en Aguilar. Defensor, 15-IV-1903

(19) -Los trabajos de las elecciones". Postremus. Semanario EEl Aviso, 8-III-1903.Montilla.

(20) .Coacciones. Defensor, 20-II-1903

(21) Los campos de Juan de Burgos se ven destrozados ante la indiferencia de los guardas rurales de Aguilar. Defensor, 6-IV-1903. 
niendo multas y recargos en las contribuciones e incluso negándose a firmar las recetas de Beneficencia ${ }^{22}$.

A juzgar por su prensa, la campaña conservadora fue un paseo triunfal en olor de multitud. El candidato, Juan de Burgos, es acompañado por personalidades conservadoras de prestigio y por los jefes locales del partido. Su más asíduo es D. Juan Mariano Algaba Pineda, candidato a diputado provincial, elegido y aclamado como presidente de la Diputación. Se trata de un gran terrateniente montillano, emparentado con las familiàs más adineradas del distrito. Acompañantes eventuales son $D$. Carlos Carrillo Tíscar, aguilarense, y los hermanos Riobóo Susbielas, originarios de Castro del Río, con tierras, parientes e influencias en Montilla, pero afincados en Montemayor.

El cacique conservador montillano, Juan Bautista Pérez Mataix, ofrece un banquete al que asiste el "todo Montilla*: Juez, jefe de guardería rural, maestros, los posaderos que alojan a los contingentes extraordinarios de la Guardia Civil, recaudadores de arbitrios... también algunos terratenientes ${ }^{23}$. Todos ellos son personajes con una posición desahogada, pero no son las grandes fortunas, que aparecen vinculadas al partido liberal demócrata o, simplemente, están más allá del bien y del mal de la política ${ }^{24}$.

Si tenemos en cuenta estas características del partido conservador, la campaña que pueden hacer no es más que de un tipo. No pueden vender grandes ideales, como los republicanos. Tampoco pueden emplear los abusos legales, porque no controlan los ayuntamientos. Sólo les queda el recurso a la propaganda clerical -sacerdote colocado por la influencia de Burgos, maderas para apuntalar la iglesia de S. Agustín de Montilla-; la captación de personalidades conocidas -Juan Abarzuza en Aguilar- o las descalificaciones al enemigo. En resumen, el uso de las influencias y el ataque despiadado que es exactamente lo que critican en los liberales.

Pero cuentan con un arma que los liberales no tienen: están en el gobierno nacional y de hecho controlan todo el proceso electoral. Maura da una circular por la que deberá haber interventores en todas las mesas electorales, pero serán nombrados por el Gobernador y no deberán obedecerlo más que a él. Y los gobernadores son todos conservadores ${ }^{25}$. Esta medida se completa con otra circular de 24 de febreropor la que los

(22) Defensor, 2-III.1903. Este punto se puede aclarar consultando el Acta de 2-III-1903 del Ayuntamiento de Montilla, donde se afirma que Marquez del Real, prototipo de caciques, tiene una actitud complaciente hacia los ganaderos que invaden determinadas fincas y no respetan los pasos obligados. En cuanto a los abusos por contribuciones y consumos, sólo su reseña ocuparía mayor extensión que la dada al presente trabajo.

(23) Defensor, 4-IV-1903

(24) Prensa local de la época: El Aviso, El Sur, Vida Nueva:

(25) Defensor, 21-II-1903 
gobernadores no pueden nombrar interventores sin la autorización del gobierno ${ }^{26}$. Esta medida, que pone en manos de los gobernadores el control efectivo de las elecciones, desata una oleada de protestas que es calificada por la prensa conservadora como "Tempestad de guardarropía $*{ }^{27}$. Los liberales acentúan sus prácticas caciquiles más o menos violentas, mientras la mayoría de la población permanece indiferente ${ }^{28}$.

El día de las elecciones vino precedido por unas jornadas de huelga general en Córdoba motivadas por el hambre y el paro, que provocaron las tradicionales cargas de la Guardia Civil y las detenciones, y remitieron tras el reparto de vales para pucheros por parte de algunos señores.

Los resultados obtenidos en el distrito de Montilla fueron los siguientes: $^{29}$

$\begin{array}{cccccrc}\text { CANDIDATO } & \text { MONTTLla } & \text { AGUILAR } & \text { CASTRO } & \text { ESPEJO } & \text { MONTEMAYOR } & \text { TOTAL } \\ \text { Juan de Burgos } & 542 & 976 & 722 & 640 & 454 & 3.334 \\ \text { Jerónimo Palma } & 1.323 & 925 & 637 & 352 & 52 & 3.289 \\ \text { Antonio Aguilar } & 764 & 872 & 636 & 226 & 213 & 2.711\end{array}$

Tanto en las votaciones como en el escrutinio se producen irregularidades. En Montilla, en el distrito $3^{2}$ sección $1^{a}$ faltan los nombres de 17 votantes. En Aguilar se han nombrado presidentes de mesa a propuesta de concejales conservadores, se ha negado el voto a diez partidarios de Jerónimo Palma; han votado 30 falsos electores; Burgos ha comprado votos a cien pesetas -el jornal del campo está a 1,25 pts. aproximadamente- $y$ ha prometido reedificar una casa para siete hermanos; un colegio ha cerrado antes de las cuatro de la tarde, hora legal.

En Espejo se amenaza a colonos con quitarles las tierras en arrendamiento si no votan a Burgos. Se aseguran el voto doblando la papeleta de una forma especial.

En Castro del Río los terratenientes conservadores han amenazado a los trabajadores. En Montemayor han emborrachado a los electores y los han obligado a votar bajo vigilancia.

Y todo ello, habiéndose nombrado los interventores por el gobernador y bajo estado de guerra.

No es de extrañar que se produjeran manifestaciones de desagrado en Montilla y Aguilar por parte republicana ante elementos conservado-

(26) Defensor, 25-II-1903

(27) Defensor, 26-II-1903

(28) Defensor, 28-II-1903, artículo titulado •Aún colea-

(29) Todas las actas del escrutinio general están en la Caja 651 A del Archivo Municipal de Montilla. 
res, disueltas por la Guardia Civil ${ }^{30}$. La prensa conservadora atribuye los incidentes post-electorales a la envidia ${ }^{31}$.

Aunque no se recoge en las actas, Rafael Jiménez Castellanos, emparentado con republicanos conservadores; afirma en el semanario .El Aviso. que fue encarcelado durante las últimas elecciones por rajar un papel. ${ }^{32}$. Al día siguiente de las elecciones son detenidos cuatro obreros por alborotar en la estación de Montilla.

En plena efervescencia post-electoral, con los obreros manifestándose en apoyo de Jerónimo Palma, el alcalde Márquez del Real hace uno de sus muy frecuentes viajes. Ya no volverá a hacerse cargo de la alcaldía. Dimite el 23 de junio y es nombrado el jefe local conservador; Juan Bautista Pérez Mataix: Alcaldes de barrio y cargos municipales son removidos. Hay que preparar las elecciones municipales.

\section{1905}

El año 1905 resultó particularmente duro. La sequía termina con la esperanza de cosecha y el hambre se suma al paro.

En abril se pone en marcha el plan de arreglo de caminos, gestionado por el diputado conservador del distrito. El conflicto alcanza una magnitud suficiente como para que el ministro de Agricultura se traslade a Córdoba a conferenciar con los organismos locales implicados ${ }^{33}$, y para que un inglés que había trabajado en la compañía eléctrica de Montilla, Mr. Harold Phillip Hastings, envíe cinco libras para el pueblo de Montilla ${ }^{34}$.

En este proceso electoral gobiernan los liberales, pero los alcaldes son conservadores.

La campaña electoral está marcada por la crisis y la corrupción inherente. En Montemayor, 150 obreros han sido trasladados a otros pueblos a tabajar, en una maniobra claramente electoralista, pero que perjudica a los obreros de los pueblos de acogida ${ }^{35}$. En Montilla, en las obras públicas no se admiten más obreros que los que voten a los liberale ${ }^{36}$.

Los rumores sobre división interna de liberales y republicanos son insistentes. D. José Fernández Jiménez, candidato liberal, envía un telegrama a ‘El Defensor de Córdoba. desmintiendo que Agustín Aguilar-

(30) Defensor, 29-IV-1903

(31) Defensor, 30-IV-1903

(32) -El Aviso', 17-V-1903. Montilla.

(33) Actas Capitulares, 21-VII-1905. Archivo Municipal de Montilla

(34) AC 8-IX-1905, Archivo Mpal, Montilla.

(35) Defensor, 31-VIII-1905

(36) .Explotando la miseria. Defensor, 1-IX-1905 
Tablada se presente por Montilla. Sin embargo, el diario conservador lo mantiene ${ }^{37}$. Unos días antes era Juan de Burgos quien tenía que desmentir su retirada. También los conservadores tienen problemas internos: Pascual Ladrón de Guevara, anterior diputado provincial conservador, pide el voto para los republicanos ${ }^{38}$.

Los republicanos ven retratadas sus luchas internas en la prensa conservadora. Se critica a Jerónimo Palma, que pide el voto para él mismo en un mítin en Castro del Río, donde la asistencia mayoritaria es de mujeres. El mitin se celebra en el Casino Republicano, usando como tribuna el balcón *alumbrado por dos faroles dignos de un puesto de uvas*39.

Unos dias antes de las elecciones, Juan de Burgos recuerda a los obreros los logros conseguidos por él, en un manifiesto publicado en Montilla el 28 de agosto y extractado por "El Defensor..." del día 4 de septiembre. Recuerda a los obreros que le deben el trabajo, y a los colonos del Duque de Uceda, en Espejo, que consiguió para ellos la suspensión del cobro de las rentas. Además, están las obras públicas de los Ayuntamientos...

Las elecciones se celebran el 10 de septiembre, y fueron muy ajetreadas. Hubo puñaladas, peleas, tiros, gritos subversivos... Se habló de un delegado muerto a puñaladas y de un intento de sublevación de varios pueblos. Cuarenta guardias civiles fueron en tren a dar posesión a un interventor... Todo son rumores y confusión ${ }^{40}$.

Los resultados, según el acta del escrutinio general, son como siguen:

$\begin{array}{lcccccc}\text { CANDIDATOS } & \text { MONTILLA } & \text { AGUILAR } & \text { CASTRO } & \text { ESPEJO } & \text { MONTEMAYOR } & \text { TOTAL } \\ \text { José Fernández } & 613 & 1.072 & 910 & 565 & 387 & 3.517 \\ \text { Jerónimo Palma } & 1.441 & 757 & 649 & 311 & 34 & 3.192 \\ \text { Juan de Burgos } & 541 & 891 & 249 & 493 & 303 & 2.477\end{array}$

Hubo, además, un voto en Montemayor para Antonio Barroso. El número de electores del distrito es de 13.981, mientras que los votantes fueron 9.188. La abstención alcanza el 34,28\% de los hombres. Los elegidos tienen una representatividad mínima.

Las protestas son abundantes. Jerónimo Palma protesta por habérsele negado la propuesta de interventores en todo el distrito y por soborno para que se vote al candidato de la mayoría. Presentará recurso

(37) Defensor, 6-IX-1905

(38) Defensor, 9-IX-1905

(39) Defensor, 2-IX-1905

(40) Defensor, 11-IX-1905 
en el Congreso, además, por el acto más grave de estas elecciones, ya bastante falseadas.

En la aldea de Zapateros, dentro del término municipal de Aguilar de la Frontera, se supone que todos los electores, 488, han votado a Fernández, lo que es falso. El candidato liberal presenta un acta notarial y rechaza las acusaciones, ateniéndose a ella y a las actas de votación.

En Castro del Río se ha producido una alteración fraudulenta de las listas, con exclusión de electores.

En Espejo y Montemayor se denuncian coacciones.

El escrutinio también fue accidentado: 13 heridos y 14 detenidos, según noticia de ‘El Imparcial• que recoge «El Defensor de Córdoba" del día 13 de septiembre.

A pesar de todo, se declara electo a José Fernández Jiménez.

Una vez más, al finalizar el proceso, se cambian los alcaldes. El de Montilla, Pérez Mataix, que estaba de permiso en las elecciones, no vuelve a hacerse cargo de la alcaldía. Lo sustituye el cacique liberal, Márquez del Realíl.

Jerónimo Palma, el gran perjudicado, impugna en el Congreso el acta de Montilla ${ }^{42}$. Se levanta una fuerte polémica en la Comisión de Actas. Junoy, republicano, pide que se declare grave, mientras García Alix, liberal, insiste en que se deje en leve. Salmerón y Vega de Armijo se reúnen para discutir el tema. Salmerón amenaza con una política de obstrucción si no se declara grave. Los contactos entre Armijo, Canalejas, Romanones y Rosales son contínuos ${ }^{43}$.

La intoxicación informativa surge, como no podía ser menos. Salta el rumor de que se va a sacrificar Montilla por Madrid, lo que desmienten rotundamente los republicanos. Este rumor está propiciado por la actitud de Salmerón, más abierto a componendas que Junoy y Gumersindo de Azcárate ${ }^{44}$.

El acta se declara leve solo con los votos de los liberales. Junoy se marcha de la Comisión 45 .

El diputado vegarmijista no cuenta con la simpatía de los concejales de Montilla, de mayoría republicana, que le niegan un voto de gracias por su gestión en la reducción del cupo de consumos mientras nombran hijo adoptivo a Jerónimo Palma Reyes ${ }^{46}$.

(41) AC 23-X-1905, Archivo Mpal, Montilla

(42) Defensor, 25-X-1905

(43) Defensor, 4-XI-1905

(44) Defensor, 7-XI-1905

(45) Defensor, 15-XI-1905

(46) AC 26-I-1906, Archivo Mpal. Montilla 


\section{1907}

Las elecciones a Cortes de este año son algo diferentes a las otras. Maura, presidente del gobierno, abomina de las prácticas caciquiles, pero cree firmemente en la revolución desde arriba. De ahí que, como primera medida, se fabrique ayuntamientos a su gusto, con el cese de concejales republicanos que cambia por monárquicos y la destitución de empleados municipales.

El alcalde Márquez del Real tiene que ceder sú poltrona de Montilla a Pérez Mataix ${ }^{47}$. En Aguilar se nombra a D. Carlos Carrillo Tíscar, hermano del cacique conservador D. Luis ${ }^{48}$.

La campaña electoral está marcada, más que nunca, por la publicidad de las divisiones internas del contrario. Como novedad, aparece el intento conservador de unificar a todos los monárquicos contra los republicanos.

La prensa local, concretamente el semanario liberal .Vida Nueva. de Montilla, intenta confundir al electorado achacando a los conservadores la falsificación de las elecciones de Zapateros y atribuyéndoles injurias al electorado de Montilla ${ }^{49}$.

El diputado liberal, Fernández, se retira de la lucha por no contar con el apoyo de los jefes ni de los electores ${ }^{50}$. Pide el voto para los republicanos, con el apoyo tácito del Marqués de la Vega de Armijo, loque hace que los conservadores lo acusen de anteponer los intereses personales a los nacionales. Aparicio y Aguilar-Tablada, también liberales destacados, piden el voto para los intereses monárquicos ${ }^{51}$.

En esta ocasión los conservadores cuentan con el apoyo explícito del Obispo, que desde las páginas del Defensor recuerda a los católicos la obligación de votar y hacerlo por quien proteja los intereses de la Iglesia (entiéndase conservadores) ${ }^{\text {s2 }}$.

La campaña sigue su curso habitual: Pérez Mataix ofrece un banquete a los conservadores del distrito, amenizado por la Banda de Música municipal de Montilla. En el transcurso del mismo se reparten mil panes a los jornaleros, medida caritativa que únicamente servirá para poner más de relieve la precaria situación de los obreros, sin trabajo por la sequía ${ }^{53}$. En Aguilar, más prácticos, ofrecen trabajo en los caminos vecinales.

(47) AC 22-III-1907 Archivo Mpal. Montilla

(48) Defensor, 2-III-1907

(49) Semanario Liberal *Vida Nueva., 22-III-1907, Montilla

(50) Vida Nueva, 27-III-1907 y Defensor, 30-III-1907

(51) Defensor, 22-IV-1907

(52) Defensor, 4 y 5-IV-1907

(53) Defensor, 6-IV-1907 
En Castro del Río Jerónimo Palma intenta ganarse a los anarquistas. En un mitin justifica el asesinato de Cánovas como un acto de justicia social, lo que desata el entusiasmo de los obreros. Ante estas circunstancias, la prensa conservadora pide el apoyo de los fernandistas para el único candidato monárquico, José Marín Cadenas.

Los ataques a los republicanos revisten todos los tonos posibles, desde el más agrio al burlesco, este último cuando presentan el programa: fin del impuesto de consumos, del servicio militar, responsabilidad de los gobernantes por el desastre de Cuba... programa que no dejaba de ser demagógico, ciertamente ${ }^{54}$.

Las elecciones se celebran sin graves incidentes el 21 de abril. Unicamente en Montilla se registran presiones de elementos liberales en favor de los republicanos. No olvidemos que Montilla es feudo del Marqués de la Vega de Armijo.

En las actas del escrutinio no se registran incidentes. Los resultados son los siguientes:

$\begin{array}{lcrrrrr}\text { CANDIDATO } & \text { MONTHLA } & \text { AGUILAR } & \text { CASTRO } & \text { ESPEjO } & \text { MONTEMAYOR } & \text { TOTAL } \\ \text { José Marín C. } & 1.155 & 1.818 & 974 & 713 & 563 & 5.223 \\ \text { Jerónimo Palma } & 1.490 & 718 & 1.047 & 522 & 92 & 3.869 \\ \text { Luis A. Aparicio } & - & - & - & - & 2 & 2\end{array}$

Montilla, Aguilar, y, en menor medida, Montemayor, suman los votos monárquicos mientras permanecen estables los votos republicanos. Castro y Espejo ven aumentar los votos republicanos, quizá como producto de la campaña de Jerónimo Palma.

La victoria conservadora se celebra en Aguilar con una fiesta conjunta de todos los monárquicos, con lo que queda patente, una vez más, que la contradicción principal no es entre liberales y conservadores, sino entre republicanos y monárquicosss.

\section{CONCLUSIONES}

La más evidente es que la práctica caciquil está fuertemente arraigada en todos los pueblos del distrito, revistiendo diferentes características y alcance según la estructura socioeconómica del pueblo. Resultan más violentas cuanto mayor es la dependencia jornalera respecto a los latifundistas, ya sea como temporeros o como colonos. En cambio, en los pueblos con más pequeños propietarios o más conflictivos socialmente el

(54) Defensor, 13-IV-1907

(55) Defensor, 23-IV-1907 
caciquismo reviste formas más suaves: reparto de pucheros, favores... pero hay pocas noticias de boicot $\mathrm{o}$ amenazas.

El abstencionismo es alto: la corrupción política, junto a la indiferencia y la incultura (el analfabetismo llega al $80 \%$ ), hace que los hombres se interesen poco por las batallas electorales. Habrá que esperar al desarrollo del socialismo para que se anime algo el cotarro político.

Las contradicciones políticas no son las que separan a conservadores de liberales. Estos son capaces de unirse contra los enemigos de las instituciones, los republicanos, que intentan a su vez atraerse al elemento obrero pero encuentran una respuesta muy tibia, en general.

A través del estudio de estos documentos, la impresión recibida es de un sistema político desconectado de la realidad social y por lo tanto condenado al fracaso. La corrupción no se puede mantener indefinidamente, y los partidos del turno no ofrecen una alternativa viable. Y los republicanos, cuando acceden al poder, repiten los esquemas de los ayuntamientos anteriores, con lo que la salida se presenta oscura y difícil. Para la mayoría de la población, los obreros, la única vía es la revolucionaria.

\section{BIBLIOGRAFIA}

Se han empleado dos libros clásicos para el estudio de la época:

- DIAZ DEL MORAL, J. Historia de las agitaciones campesinas andaluzas. Alianza Universidad.

- CARR, R. España 1808-1975. Ed. Ariel 